\title{
Cardiac MRI in Children and Adolescents Who Have Undergone Surgical Repair of Right-Sided Congenital Heart Disease: Automated Left Ventricular Volumes and Function Analysis and Effects of Different Manual Adjustments
}

\author{
Kardiale MRT bei Kindern und Jugendlichen mit operativ korrigierter angeborener Rechtsherz- \\ Pathologie: Automatische Volumen- und Funktionsanalyse des linken Ventrikels und Einfluss \\ unterschiedlicher manueller Korrekturen
}

Authors

Affiliations

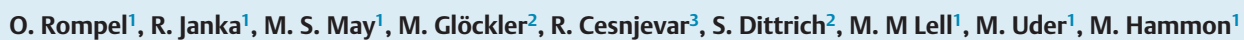

Department of Radiology, University Hospital Erlangen, Germany

Department of Pediatric Cardiology, University Hospital Erlangen, Germany

Department of Pediatric Cardiac Surgery, University Hospital Erlangen, Germany

Key words
MR imaging
segmentation
heart
left ventricle
manual adjustment
pediatrics

received $\quad 8.1 .2015$

accepted 24.6.2015

Bibliography

Dol http://dx.doi.org/ 10.1055/s-0035-1553418

Published online: 1.9.2015

Fortschr Röntgenstr 2015; 187: 1099-1107 @ Georg Thieme Verlag KG Stuttgart · New York ISSN 1438-9029

\section{Correspondence}

Herr Dr. Matthias Hammon Radiologisches Institut, Universitätsklinikum Erlangen Maximiliansplatz 1 91054 Erlangen Germany

Tel.: ++ 49/0 $9131 / 8536065$

Fax: ++49/0 9131/8536068 matthias.hammon@uk-

erlangen.de

\section{Zusammenfassung \\ $\nabla$}

Ziel: Diese Studie untersucht die Genauigkeit der automatisierten Segmentierung und den Einfluss unterschiedlicher manueller Korrekturen bezüglich der linksventrikulären Parameter in Magnetresonanztomografie (MRT)-Untersuchungen von Kindern und Jugendlichen mit operativ korrigierter, angeborener Rechtsherz-Pathologie.

Material und Methoden: Die automatische Segmentierung und die unterschiedlichen manuellen Korrekturen wurden mit einer dedizierten Software durchgeführt (syngo.via, Siemens AG). Das end-diastolische Volumen (EDV), end-systolische Volumen (ESV), Schlagvolumen (SV), die myokardiale Masse (MM) und Ejektionsfraktion (EF) wurden vor/nach manueller Apex-/Basiskorrektur (Korrekturschritt 1) und nach manueller Apex-/Basis-/Myokardkontur-Korrektur (Korrekturschritt 2; Referenzstandard) dokumentiert. MRT-Datensätze von 40 Patienten (13,1 $\pm 3,1$ Jahre, 4-17 Jahre) mit operativ korrigierter, angeborener Rechtsherz-Pathologie mit reduziertem pulmonalen Blutfluss wurden evaluiert. Die Intra- und Inter-rater-Reliabilität wurde für $10 \mathrm{zu}$ fällig ausgewählte Patienten bestimmt.

Ergebnisse: Der linke Ventrikel wurde bei 38/40 Patienten korrekt von der Software detektiert (95\%). Das automatisch segmentierte EDV betrug $119,1 \pm 44,0 \mathrm{ml}$, nach Korrekturschritt 1: 115,8 $\pm 39,5 \mathrm{ml}$, nach Korrekturschritt 2: 116,2 $\pm 39,4 \mathrm{ml}$. Die entsprechenden Ergebnisse für das ESV waren $52,0 \pm 18,5 / 49,6 \pm 16,9 / 49,7 \pm 16,4 \mathrm{ml}$, für das $S V$ $67,1 \pm 28,5 / 66,2 \pm 25,4 / 66,5 \pm 25,5 \mathrm{ml}$, für die $\mathrm{EF}$ $55,5 \pm 7,3 / 56,7 \pm 6,6 / 56,7 \pm 6,3 \%$, für die MM 83,7 $\pm 35,9 / 76,2 \pm 28,3 / 74,6 \pm 27,2$ g. Signifikante Unterschiede traten zwischen dem ESV/der MM/EF nach der automatischen Segmentierung verglichen mit den Ergebnissen nach Korrekturschritt 1 und Korrekturschritt 2 auf. Kein signifikanter Unterschied war zwischen allen Ergebnissen nach Korrekturschritt 1 und Korrekturschritt 2 und zwischen den

\section{Abstract \\ $\nabla$}

Purpose: To evaluate automated segmentation and the effects of different manual adjustments regarding left ventricular parameter quantification in cardiac magnetic resonance (MR) data on children and adolescents who have undergone surgical repair of right-sided congenital heart disease (CHD).

Materials and Methods: Dedicated software (syngo.via, Siemens AG) was used to automatically segment and/or manually adjust the end-diastolic volume (EDV), end-systolic volume (ESV), stroke volume (SV), myocardial mass (MM) and ejection fraction (EF) before/after manual apex/base adjustment (ADJ-step 1) and after manual apex/ base/myocardial contour adjustment (ADJ-step 2; reference standard). MR data of 40 patients (13.1 \pm $3.1 \mathrm{y}, 4-17 \mathrm{y})$ with repaired CHD with decreased pulmonary blood flow (CHD-DPBF) were evaluated. Intra- and inter-rater reliability was determined for 10 randomly selected patients.

Results: The software correctly detected the left ventricle in 38/40 (95\%) patients. EDV after automated segmentation: $119.1 \pm 44.0 \mathrm{ml}$; after ADJstep 1: $115.8 \pm 39.5 \mathrm{ml}$; after ADJ-step 2: $116.2 \pm$ $39.4 \mathrm{ml}$. The corresponding results for ESV were $52.0 \pm 18.5 / 49.6 \pm 16.9 / 49.7 \pm 16.4 \mathrm{ml}$; for SV $67.1 \pm$ $28.5 / 66.2 \pm 25.4 / 66.5 \pm 25.5 \mathrm{ml}$; for EF $55.5 \pm 7.3 /$ $56.7 \pm 6.6 / 56.7 \pm 6.3 \%$; for MM $83.7 \pm 35.9 / 76.2 \pm$ $28.3 / 74.6 \pm 27.2 \mathrm{~g}$. Significant differences were found for ESV/MM/EF comparing the automated segmentation results with these after ADJ-step 1 and ADJ-step 2. No significant differences were found when comparing all results of ADJ-step 1 and ADJ-step 2 or when comparing EDV/SV results. Intra- and inter-rater reliability was excellent. The mean time effort was $63.4 \pm 6.9 \mathrm{~s}$ for the automated segmentation, $74.2 \pm 8.9 \mathrm{~s}$ for ADJ-step 1 and $269.5 \pm 39.4 \mathrm{~s}$ for ADJ-step 2 .

Conclusion: Automated left ventricular volumes and function analysis in children and adolescents 
EDV/SV festzustellen. Die Intra- und Inter-rater-Reliabilität war exzellent. Der durchschnittliche Zeitaufwand betrug $63,4 \pm 6,9 \mathrm{~s}$ für die automatische Segmentierung, 74,2 $\pm 8,9$ s für Korrekturschritt 1 und 269,5 $\pm 39,4$ s für Korrekturschritt 2.

Schlussfolgerung: Eine automatische Volumen- und Funktionsanalyse des linken Ventrikels bei Kindern und Jugendlichen mit operativ korrigierter angeborener Rechtsherz-Pathologie ist mit einer exzellenten Intra- und Inter-rater-Reliabilität möglich. Die automatische Segmentierung mit manueller Apex-/Basiskorrektur lieferte akzeptable Ergebnisse für den Großteil der Patienten. Kernaussagen:

- Eine automatische Volumen- und Funktionsanalyse des linken Ventrikels bei Kindern und Jugendlichen mit operativ korrigierter angeborener Rechtsherz-Pathologie ist mit einer exzellenten Intra- und Inter-rater-Reliabilität möglich.

- Die automatische Segmentierung mit manueller Apex-/BasisKorrektur liefert akzeptable Ergebnisse für den Großteil der Patienten.

- Die zusätzliche manuelle Korrektur der Myokardkontur führt zu keiner signifikanten Verbesserung der Ergebnisse.

\section{Introduction}

$\nabla$

Right-sided congenital heart disease (CHD) can be classified into inborn defects with increased and decreased pulmonary blood flow (CHD-DPBF), the latter including Tetralogy of Fallot (TOF), pulmonary atresia (PA), Ebstein's anomaly and tricuspid atresia [1]. The current treatment of the majority of patients with CHDDPBF consists of complete biventricular corrective surgery, preferably within the first months of life [2]. In this population postoperative anatomic and hemodynamic abnormalities are almost universal. These include right ventricular dilatation due to pulmonary valve regurgitation or homograft failure, aneurysm or obstruction of the right ventricular outflow tract (RVOT), pulmonary artery stenosis, residual atrial or ventricular septal defect, aortic root dilatation or aorto-pulmonary collateral supply [3]. Cardiac magnetic resonance (MR) imaging has emerged as an essential diagnostic tool in the investigation of these patients after surgery. It allows a comprehensive assessment of the abnormalities mentioned before [3 - 5]. The advantages of MR imaging over other imaging techniques are its robust image quality, the excellent blood/myocardial contrast and the fact that there is no ionizing radiation with its associated stochastic radiation effects, which is a critical consideration for children and adolescents [6]. Vascular and valvular flow patterns and volumes can be assessed and shunts can be quantified [7, 8]. Moreover, it is well-known that MR is an accurate and reproducible technique for the assessment of left and right ventricular volumes and function $[6,8,9]$.

For the quantification of right ventricular volumes, laborious manual measurement is still the most accurate post-processing methodology $[8,10]$.

For the quantification of the left ventricle, several techniques for semi- and fully automatic segmentation of the left ventricular parameters in diastole and systole have been proposed for adult patients to support readers during the time-consuming segmentation task [11 - 27]. Because available algorithms are usually based on adult hearts, left ventricular segmentation might be affected in the data of children and adolescents. Specifically, surgical treatment of CHD might affect the anatomy, morphology or location of the left ventricle. Hence, numerous user interactions might be nec- with surgically treated CHD proved to be feasible with excellent intra- and inter-rater reliability. Automated segmentation with manual apex/base adjustment provided clinically acceptable results.

Key Points:

- Automated left ventricular volume and function analysis in children and adolescents with surgically treated right-sided heart disease is feasible with excellent intra- and inter-rater reliability.

- Automated segmentation with manual apex/base adjustment provides clinically acceptable results.

- Additional manual myocardial contour adjustment does not significantly improve the results.

Citation Format:

- Rompel O, Janka R, May MS et al. Cardiac MRI in Children and Adolescents Who Have Undergone Surgical Repair of Right-Sided Congenital Heart Disease: Automated Left Ventricular Volumes and Function Analysis and Effects of Different Manual Adjustments. Fortschr Röntgenstr 2015; 187: 1099-1107 essary to define the border of the left ventricle. Neither the reliability of automatic detection/segmentation of the left ventricle nor the effects of manual adjustments and the value of long-axis consideration have previously been investigated using the MR data of children and adolescents with repaired CHD.

Therefore, this study was set up to evaluate the automated segmentation of left ventricular volumes and function in cardiac MR images of children and adolescents who have undergone surgical repair of right-sided CHD using commercially available software and to identify the effects of different manual adjustment steps.

\section{Materials and Methods}

This study was conducted in accordance with the guidelines of the Declaration of Helsinki and approved by the Ethics Committee of the University Hospital Erlangen. The need for written informed consent was waived by the Ethics Committee.

\section{Patient population}

We retrospectively evaluated left ventricular parameters of 40 consecutive surgically treated children and adolescents presenting CHD with former DPBF in cardiac MR imaging (22 male, 18 female; $13.1 \pm 3.1$ years; range: $4-17$ years). Repaired TOF was present in 23 patients, PA with ventricular septal defect (VSD) in 12 patients, PA without VSD in 3 patients and Ebstein's anomaly in 2 patients. The body surface area was calculated with a formula proposed by Mosteller [28]: body surface area (in $\mathrm{m}^{2}$ ) equals the square root of height (in $\mathrm{cm}$ ) multiplied by weight (in $\mathrm{kg}$ ), all divided by 3600 . All patients were examined from March 2010 to February 2014. Patient characteristics, depending on automatic detection success of the left ventricle, are given in $\bullet$ Table 1.

\section{Imaging technique}

MR examinations were performed on a 1.5 Tesla MR scanner equipped with high-performance gradients (Magnetom Aera, Siemens AG, Erlangen, Germany). The imaging protocol routinely included balanced steady-state free precession (bSSFP) cine sequences for functional and volumetric analysis of both ventricles. 
Phase-contrast MR imaging was acquired for the quantification of the pulmonary to systemic blood flow ratio (Qp:Qs), valvular regurgitation fractions and the flow velocity through valvular or vascular stenoses. Contrast-enhanced MR angiography was conducted for $3 \mathrm{D}$ depiction of the morphology of the right ventricular outflow tract, the pulmonary arteries and the aortic arch. Individual optimization of sequences was necessary depending on anatomic or pathologic findings and the patient's cooperation and breath-holding capacity. For the left ventricle, retrospectively gated electrocardiographically triggered bSSFP cine images were acquired during breath holding in standard four-chamber, three-chamber, and two-chamber long- as well as short-axis views covering the entire left ventricle with a $10 \%$ slice gap. Scan parameters in all patients were as follows: slice thickness $8 \mathrm{~mm}$, in-plane resolution $2.5 \times 1.8 \mathrm{~mm}$, time to echo (TE) $1.1 \mathrm{~ms}$, time to repetition (TR) $42 \mathrm{~ms}$ and flip angle $50^{\circ}$.

Patients were imaged in the supine position. We only administered general anesthesia to a 4-year-old boy. In all other patients older than 7 years, neither sedation nor mechanical ventilation was necessary.

\section{Segmentation methods}

Quantitative image data analysis was performed using dedicated commercially available software that enables post-processing of cardiac MR data (syngo.via, Siemens AG, Erlangen, Germany). The left ventricle was judged to be successfully detected by the software if the left ventricle rather than a different anatomical structure was marked. Results of end-diastolic volume, end-systolic volume, stroke volume, myocardial mass as well as the automatically calculated ejection fraction were documented before and after each step of manual adjustment. End-diastolic and end-systolic volumes were calculated by summing the volume of the left ventricular blood pool in each section. Ejection fraction was calculated on the basis of end-diastolic and end-systolic volumes as [(end-diastolic volume - end-systolic volume)/enddiastolic volume] $\times 100$ (\%). The myocardial mass of the left ventricle was measured at end diastole by multiplying the myocardial volume by the specific gravity of the myocardium $(1.05 \mathrm{~g} /$ $\mathrm{ml})$. All results were documented as absolute values and not divided by the body surface area (BSA) in order to allow better comparability of the different methods.

To eliminate operator-related differences, adjustments were performed in consensus by three experienced readers with more than 8 (R.J.), more than 6 (O.R) and more than 4 (M.H.) years of experience in the interpretation of cardiac MR images. The readers evaluated the studies in random order and were blinded to patient characteristics. In the case of failed automated segmentation, manual short-axis planimetry (=marking of the outer and inner myocardial contour in every slice) and determination of the ventricle's base in long-axis images (equals the results after automated segmentation and apex/base/myocardial contour adjustment = ADJ step 2) was performed.

\section{Automated segmentation}

MR images (four-chamber, three-chamber, and two-chamber long- as well as short-axis views) were automatically transferred to the syngo.via server and the calculations were performed. Left ventricular detection and segmentation results were analyzed and absolute values of end-diastolic volume, end-systolic volume, myocardial mass and ejection fraction were documented without performing any manual adjustments.
Adjustment step 1 (ADJ-step 1): Automated segmentation and manual apex/base adjustment

On the basis of the results of automated segmentation, manual apex and base adjustments were performed in consensus: The last apical slice was defined as the most apical short-axis view showing intracavitary blood pool. Long-axis images (four-chamber, three-chamber, and two-chamber views) were used to define the base of the left ventricle.

\section{Adjustment step 2 (ADJ-step 2): Automated} segmentation, manual apex/base adjustment and manual myocardial contour adjustment

On the basis of the results of ADJ-step 1, endo- and epicardial myocardial borders of each short-axis image from the base to the apex were identified and manually adjusted at end diastole and end systole. Papillary muscles were considered to be part of the left ventricular cavity. For mass calculations, the interventricular septum was added to the left ventricle. These parameters were considered to be the reference standard.

The different adjustment steps are illustrated in $\bullet$ Fig. 1.

Intra- and inter-rater reliability

For 10 randomly selected patients from the investigated cohort (mean age: 12.9 years), the evaluation was performed twice in consensus and independently by three different readers. Intraclass correlation coefficients and coefficients of variation were calculated.

\section{Time effort for the automated segmentation and the adjustment steps}

The mean time effort for the automated segmentation and for the two adjustment steps was recorded for 10 randomly selected patients.

\section{Statistical analysis}

Data are expressed as means \pm standard deviations and range. Bland-Altman plots were prepared to compare the end-diastolic volume, end-systolic volume and myocardial mass parameters of automated segmentation with the parameters of ADJ-step 2 (automated segmentation + apex/base/myocardial contour adjustment; considered to be the reference standard) and to compare the parameters of ADJ-step 1 (automated segmentation + apex/ base adjustment) with the parameters of ADJ-step 2 (automated segmentation + apex/ base/myocardial contour adjustment). Differences between means of the different segmentation methods were assessed using the Student's t-test for normally distributed dependent samples. Throughout the analysis, a two-sided $p$-value $<0.05$ was considered statistically significant. To show reproducibility, intra-class correlation coefficients and coefficients of variation were determined for 10 randomly selected patients that were evaluated twice. Intra-class correlation coefficients were calculated for the 10 randomly selected patients that were evaluated independently by three different readers. The coefficient of variance represents the ratio of the standard deviation to the mean. Statistical analysis was performed using dedicated software (SPSS Statistics v20, IBM Corp., Armonk, NY).

\section{Results}

\section{$\nabla$}

MR image quality was satisfactory in all examinations. The software successfully detected and segmented the left ventricle in 38 

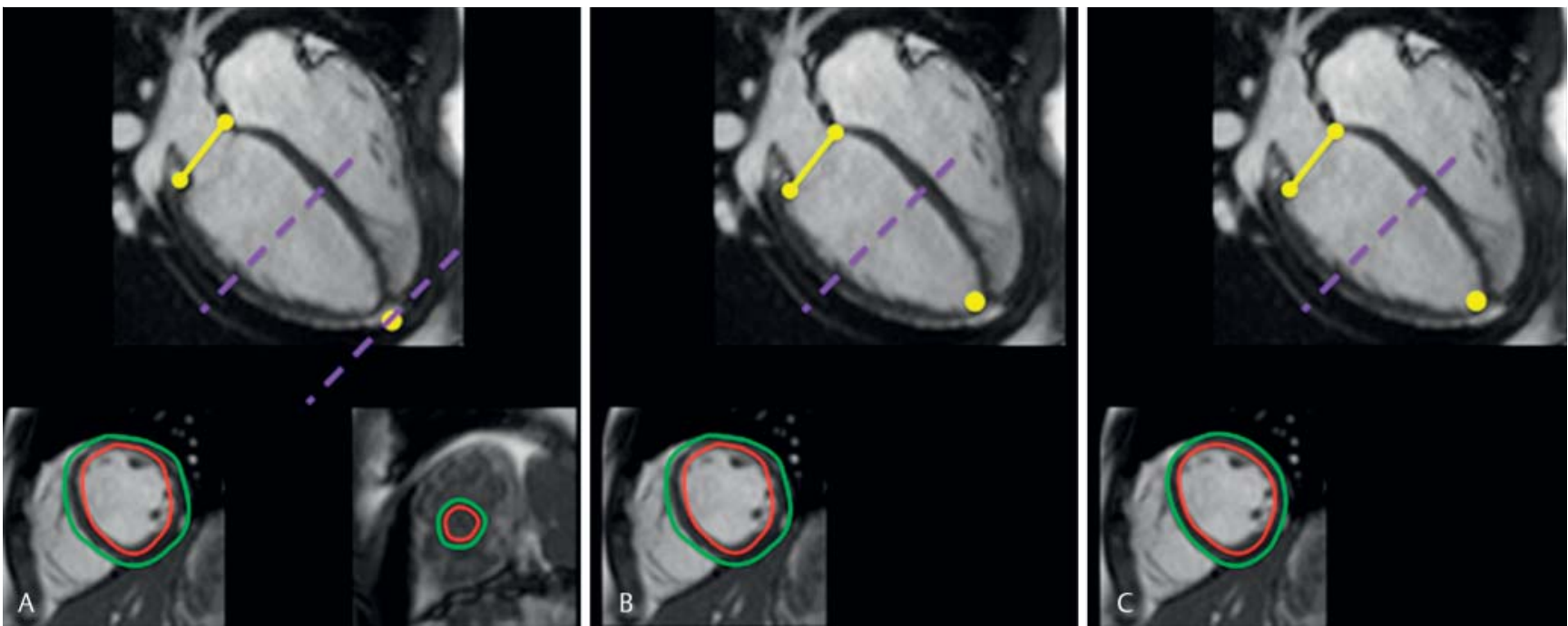

Fig. 1 Four-chamber long-axis views (upper) and exemplary short-axis views of the left ventricle (lower). The purple lines indicate the location of the axial views shown. The yellow markings label the mitral valve and the apex of the left ventricle. The endo- and epicardial myocardial borders are delineated with red and green lines, respectively. A After automated segmentation: Good delineation of the mitral valve. At the apex a slice without intracavitary blood pool was segmented. Good detection of the endo- and epicardial myocardial borders. B After manual apex/base adjustment (ADJstep 1). The primary last apical slice was deleted and slight adjustment of the mitral valve was performed. C After manual apex/base/myocardial contour adjustment (ADJ-step 2). On the basis of the results of ADJ-step 1, endo- and epicardial myocardial borders of each short-axis image from the base to the apex were identified and manually adjusted at end diastole and end systole.
Abb. 1 Vier-Kammer-Langachsenschnitte (oben) und exemplarische Kurzachsenschnitte des linken Ventrikels (unten). Die lilafarbenen Linien zeigen die Lokalisation der Kurzachsenschnitte. Die gelben Markierungen entsprechen der Mitralklappe und dem Apex des linken Ventrikels. Die endo- und epikardiale Begrenzung des Myokards ist mit einer roten bzw. grünen Linie markiert. A Nach automatischer Segmentierung: Die Mitralklappe wurde gut erkannt. Apikal wurde eine Schicht ohne intrakavitärem Blood-Pool segmentiert. Die Epi- und Endokonturen sind gut eingezeichnet. B Nach manueller Apex-/Basis-Korrektur (Korrekturschritt 1): Die Apexposition wurde korrigiert, hierdurch fällt die ursprünglich segmentierte letzte apikale Schicht weg. Geringe Korrektur der Position der Mitralklappe. C Nach manueller Apex-/Basis-/Myokardkontur-Korrektur (Korrekturschritt 2). Auf der Grundlage der Ergebnisse des Korrekturschritts 1 wurden sämtliche enddiastolischen und endsystolischen Epi- und Endokardkonturen auf den Kurzachsenschnitten manuell angepasst.

Table 1 Patient characteristics divided into groups depending on the automated detection success of the left ventricle. Age, end-diastolic volume, end-systolic volume and myocardial mass are given as means \pm standard deviations and ranges. Results after automated segmentation + apex/base/myocardial contour adjustment (ADJ-step 2) are shown (these results served as a reference standard). The left ventricle was judged to be successfully detected by the software if the left ventricle rather than a different anatomical structure was marked.

Tab. 1 Patientenmerkmale abhängig vom Erfolg der automatischen Detektion des linken Ventrikels. Alter, enddiastolisches Volumen, endsystolisches Volumen und myokardiale Masse als Durchschnittswerte \pm Standardabweichung und der Spannweite. Die Ergebnisse nach der automatischen Segmentierung + Apex-/Basis-/Myokardkontur-Korrektur (Korrekturschritt 2, ADJ-step 2) sind angegeben (diese Ergebnisse dienten als Referenzstandard). Der linke Ventrikel wurde als von der Software korrekt detektiert bezeichnet, wenn er und nicht eine andere anatomische Struktur markiert wurde.

\begin{tabular}{|c|c|c|}
\hline & $\begin{array}{l}\text { successful detection and segmentation of the left ventricle } \\
(\mathrm{n}=38 ; 95 \%)\end{array}$ & $\begin{array}{l}\text { failed detection of the left ventricle } \\
(n=2 ; 5 \%)\end{array}$ \\
\hline age (years) & $13.1 \pm 3.1(4-17)$ & $13.5 \pm 0.7(13,14)$ \\
\hline gender & $21 \times$ male, $17 \times$ female & $1 \times$ male, $1 \times$ female \\
\hline body surface area $\left(\mathrm{m}^{2}\right)$ & $1.42 \pm 0.32(0.61-1.93)$ & $1.35 \pm 0.14(1.25,1.45)$ \\
\hline end-diastolic volume (ml) & $116.2 \pm 39.4(35.2-207.8)$ & $101.2 \pm 0.8(100.6-101.8)$ \\
\hline end-systolic volume (ml) & $49.7 \pm 16.4(15.1-91.6)$ & $68.7 \pm 1.1(67.9-69.5)$ \\
\hline myocardial mass $(\mathrm{g})$ & $74.6 \pm 27.2(21.9-157.6)$ & $63.4 \pm 22.6(47.4-79.4)$ \\
\hline type of disease & $23 \times$ TOF, $12 \times$ PA with VSD, $3 \times$ PA without VSD & $2 \times$ Ebstein's anomaly \\
\hline
\end{tabular}

Total $n=40$; TOF $=$ Tetralogy of Fallot, $\mathrm{PA}=$ pulmonary atresia, $\mathrm{VSD}=$ ventricular septal defect.

$\mathrm{n}=40 ; \mathrm{TOF}=$ Fallot-Tetralogie, PA = Pulmonalatresie, VSD = Ventrikelseptumdefekt.

of 40 patients (95\%). The parameters of correctly detected/segmented left ventricles are as follows: Age: $13.1 \pm 3.1(4-17)$ years, body surface area $\left(\mathrm{m}^{2}\right): 1.42 \pm 0.32(0.61-1.93)$, end diastolic volume: $116.2 \pm 39.4 \mathrm{ml}, 35.2-207.8 \mathrm{ml}$, end-systolic volume: $49.7 \pm 16.4 \mathrm{ml}, 15.1-91.6 \mathrm{ml}$, myocardial mass: $74.6 \pm$ $27.2 \mathrm{~g}, 21.9-157.6 \mathrm{~g}$. The software failed to detect the patient's left ventricle in 2 cases (5\%). Both patients presented Ebstein's anomaly with a severely dilated right atrium and a displaced left ventricle (age: 13 and 14 years, body surface area $\left(\mathrm{m}^{2}\right): 1.35 \pm$ 0.14 (1.25, 1.45), end-diastolic volume: $101.2 \pm 0.8 \mathrm{ml}, 100.6-$ $101.8 \mathrm{ml}$, end-systolic volume: $68.7 \pm 1.1 \mathrm{ml}, 67.9$ - $69.5 \mathrm{ml}$, myocardial mass: $63.4 \pm 22.6 \mathrm{ml}, 47.4-79.4 \mathrm{~g}$ ). Detailed information is shown in $\bullet$ Table 1. 
Table 2 Morphological and functional parameters of the left ventricle of automated segmentation and after different manual adjustment steps. Statistically significant differences were found for end-systolic volume/myocardial mass/ejection fraction when comparing the automated segmentation results with these after ADJ-step 1 (automated segmentation + manual adjustment of the apex/base) and ADJ-step 2 (automated segmentation + manual adjustment of the apex/ base/myocardial contour). No significant differences were found when comparing all results of ADJ-step 1 and ADJ-step 2 or when comparing end-diastolic/ stroke volume results. Data are given as means \pm standard deviations. Total $n=38$. Stroke volume $=$ end-diastolic volume - end-systolic volume. Ejection fraction $=[($ end-diastolic volume - end-systolic volume $) /$ end-diastolic volume $] \times 100(\%)$

Tab. 2 Morphologische und funktionelle Parameter des linken Ventrikels der automatischen Segmentierung und nach unterschiedlichen manuellen Korrekturschritten. Statistisch signifikante Unterschiede traten beim endsystolischen Volumen/der myokardialen Masse/Ejektionsfraktion auf, wenn man die Ergebnisse der automatischen Segmentierung mit denen nach Korrekturschritt 1 (ADJ-step 1; automatische Segmentierung + manueller Apex-/Basiskorrektur) und mit denen nach Korrekturschritt 2 (ADJ-step; automatische Segmentierung + manueller Apex-/Basis-/Myokardkonturkorrektur) verglich. Kein signifikanter Unterschied trat auf, wenn man sämtliche Ergebnisse nach Korrekturschritt 1 und Korrekturschritt 2 und die Ergebnissen des enddiastolischen Volumens/ Schlagvolumens verglich. Die Ergebnisse sind als Durchschnittswerte \pm Standardabweichung angegeben. $\mathrm{n}=38$, Schlagvolumen = enddiastolisches Volumen endsystolisches Volumen. Ejektionsfraktion $=[($ enddiastolisches Volumen - endsystolisches Volumen $) /$ enddiastolisches Volumen $] \times 100(\%)$.

\begin{tabular}{|c|c|c|c|c|}
\hline & $\begin{array}{l}\text { automated seg- } \\
\text { mentation (AS) }\end{array}$ & $\begin{array}{l}\text { automated segmentation }+ \\
\text { apex/base adjustment } \\
\text { (ADJ-step 1) }\end{array}$ & $\begin{array}{l}\text { automated segmentation }+ \\
\text { apex/base/myocardial con- } \\
\text { tour adjustment } \\
(\text { ADJ-step 2) }\end{array}$ & p-values \\
\hline end-diastolic volume (ml) & $119.1 \pm 44.0$ & $115.8 \pm 39.5$ & $116.2 \pm 39.4$ & $\begin{array}{l}\text { AS vs. ADJ-step 1: } 0.09 \\
\text { AS vs. ADJ-step 2: } 0.2 \\
\text { ADJ-step } 1 \text { vs. ADJ-step 2: } 0.4\end{array}$ \\
\hline end-systolic volume (ml) & $52.0 \pm 18.5$ & $49.6 \pm 16.9$ & $49.7 \pm 16.4$ & $\begin{array}{l}\text { AS vs. ADJ-step 1: } 0.00 \\
\text { AS vs. ADJ-step 2: } 0.009 \\
\text { ADJ-step } 1 \text { vs. ADJ-step 2: } 0.8\end{array}$ \\
\hline stroke volume (ml) & $67.1 \pm 28.5$ & $66.2 \pm 25.4$ & $66.5 \pm 25.5$ & $\begin{array}{l}\text { AS vs. ADJ-step 1: } 0.6 \\
\text { AS vs. ADJ-step 2: } 0.7 \\
\text { ADJ-step } 1 \text { vs. ADJ-step 2: } 0.2\end{array}$ \\
\hline myocardial mass (g) & $83.7 \pm 35.9$ & $76.2 \pm 28.3$ & $74.6 \pm 27.2$ & $\begin{array}{l}\text { AS vs. ADJ-step 1: } 0.002 \\
\text { AS vs. ADJ-step 2: } 0.001 \\
\text { ADJ-step } 1 \text { vs. ADJ-step 2: } 0.2\end{array}$ \\
\hline ejection fraction (\%) & $55.5 \pm 7.3$ & $56.7 \pm 6.6$ & $56.7 \pm 6.3$ & $\begin{array}{l}\text { AS vs. ADJ-step 1: } 0.03 \\
\text { AS vs. ADJ-step 2: } 0.03 \\
\text { ADJ-step } 1 \text { vs. ADJ-step 2: } 0.99\end{array}$ \\
\hline
\end{tabular}

${ }^{1}$ These parameters are considered to be the reference standard.

Diese Ergebnisse werden als Referenzstandard betrachtet.

The initial automatically segmented, non-adjusted end-diastolic volume was $119.1 \pm 44.0 \mathrm{ml}$, the end-systolic volume was $52.0 \pm$ $18.5 \mathrm{ml}$, the stroke volume was $67.1 \pm 28.5 \mathrm{ml}$, the myocardial mass was $83.7 \pm 35.9 \mathrm{~g}$ and the ejection fraction was $55.5 \pm 7.3 \%$. After the manual adjustment of the apex (short-axis images) and the base of the left ventricle (long-axis images) (=ADJ-step 1), the end-diastolic volume was $115.8 \pm 39.5 \mathrm{ml}$, the end-systolic volume was $49.6 \pm 16.9 \mathrm{ml}$, the stroke volume was $66.2 \pm 25.4 \mathrm{ml}$, the myocardial mass was $76.2 \pm 28.3 \mathrm{~g}$ and the ejection fraction was $56.7 \pm 6.6 \%$.

After the manual adjustment of the apex/base and the shortaxis images of the left ventricle (refinement of the myocardial segmentation) (=ADJ-step 2 ), the end-diastolic volume was $116.2 \pm 39.4 \mathrm{ml}$, the end systolic volume was $49.7 \pm 16.4 \mathrm{ml}$, the stroke volume was $66.5 \pm 25.5 \mathrm{ml}$, the myocardial mass was $74.6 \pm 27.2 \mathrm{~g}$ and the ejection fraction was $56.7 \pm 6.3 \%$.

Comparing the parameters of automated segmentation with those of ADJ-step 1 (automated segmentation + manual adjustment of the apex/base), the difference was $3.3 \mathrm{ml}$ (2.8\%) for the mean end-diastolic volume, $2.4 \mathrm{ml}$ (4.6\%) for the mean end-systolic volume, $0.9 \mathrm{ml}(1.3 \%)$ for the mean stroke volume, $7.5 \mathrm{~g}$ (9.0\%) for the mean myocardial mass and $1.2 \%(2.1 \%)$ for the mean ejection fraction.

Comparing the parameters of automated segmentation with those of ADJ-step 2 (automated segmentation + manual adjustment of the apex/base/myocardial contour), the difference was $2.9 \mathrm{ml}(2.4 \%)$ for the mean end-diastolic volume, $2.3 \mathrm{ml}(4.4 \%)$ for the mean end-systolic volume, $0.6 \mathrm{ml}(0.9 \%)$ for the mean stroke volume, $9.1 \mathrm{~g}(10.9 \%)$ for the mean myocardial mass and $1.2 \%(2.1 \%)$ for the mean ejection fraction.

Comparing the parameters of ADJ-step 1 (automated segmentation + manual adjustment of the apex/base) with those of ADJstep 2 (automated segmentation + manual adjustment of the apex/base/myocardial contour), the difference was $0.4 \mathrm{ml}(0.3 \%)$ for the mean end-diastolic volume, $0.1 \mathrm{ml}(0.2 \%)$ for the mean end-systolic volume, $0.3 \mathrm{ml}(0.5 \%)$ for the mean stroke volume, $1.6 \mathrm{~g}(2.1 \%)$ for the mean myocardial mass and $0 \%$ for the mean ejection fraction.

Statistically significant differences were found for the end-systolic volume/myocardial mass/ejection fraction comparing the automated segmentation results with these after ADJ-step 1 (automated segmentation + manual adjustment of the apex/base) and ADJ-step 2 (automated segmentation + manual adjustment of the apex/base/myocardial contour). No significant differences were found when comparing all results of ADJ-step 1 and ADJ-step 2 or when comparing the end-diastolic/stroke volume results. Morphological and functional left ventricular parameters are summarized in $\bullet$ Table 2 and in $\bullet$ Fig. $2,3$.

Intra-class correlation coefficients (ICC) and coefficients of variation indicated excellent intra-rater reliability. The ICC was 0.99 for all measurements and the coefficients of variation ranged from $0.9 \%$ to $2.0 \%$. Furthermore, the ICCs indicated excellent inter-rater reliability (range: 0.91 to 0.99 ). 


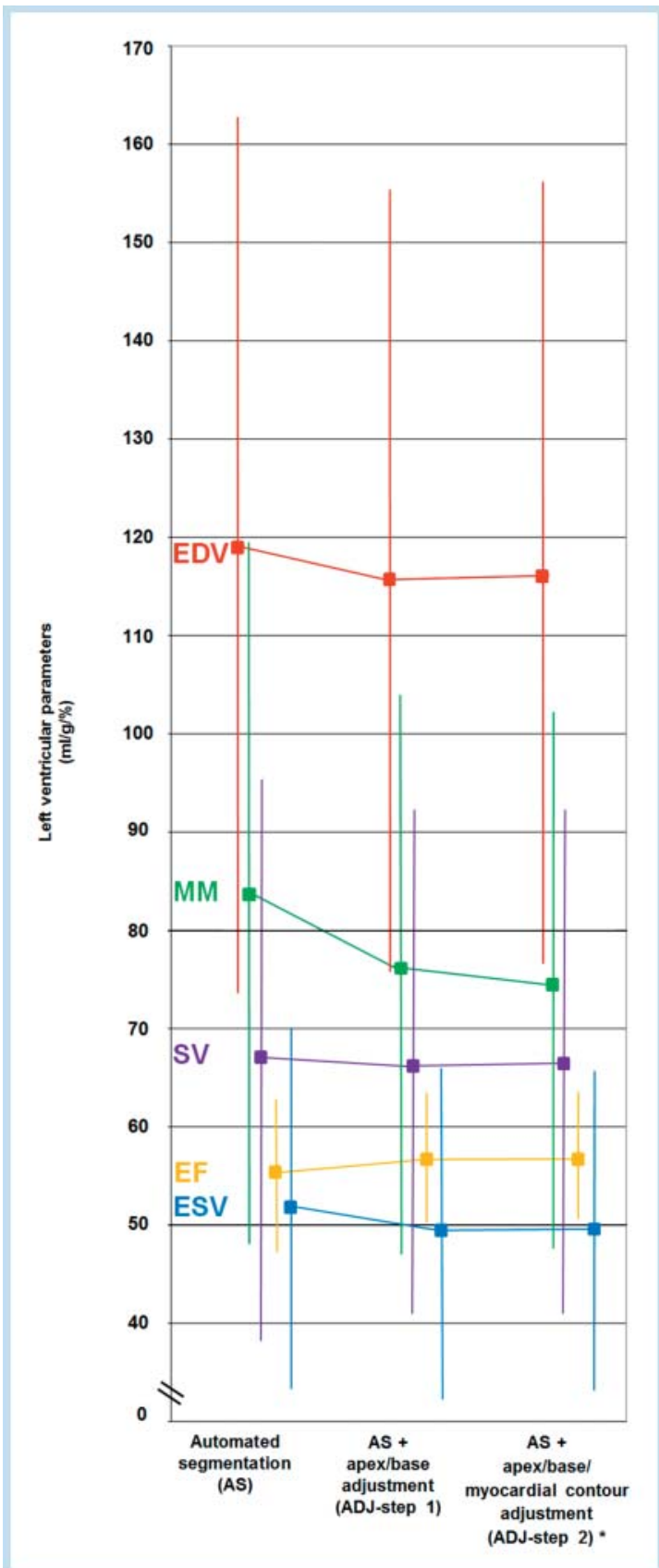

Fig. 2 Morphological and functional parameters of the left ventricle of automated segmentation and after different manual adjustment steps. Data are given as means \pm standard deviations. Red = end-diastolic volume $(E D V ; m l)$, blue = end-systolic volume $(E S V ; m l)$, purple = stroke volume (SV; $\mathrm{ml})$, green $=$ myocardial mass $(\mathrm{MM} ; \mathrm{g})$, orange $=$ ejection fraction $(\mathrm{EF} ; \%)$. Stroke volume $=$ end-diastolic volume - end-systolic volume. Ejection fraction $=[($ end-diastolic volume - end-systolic volume $) /$ end-diastolic volume $]$ $\times 100(\%)$. Total $n=38$.

* These parameters are considered to be the reference standard.

Abb. 2 Morphologische und funktionelle Parameter des linken Ventrikels der automatischen Segmentierung und nach unterschiedlichen manuellen Korrekturen. Die Ergebnisse sind als Mittelwerte \pm Standardabweichung angegeben. Rot $=$ enddiastolisches Volumen $(E D V ; ~ m l)$, blau = endsystolisches Volumen (ESV; $\mathrm{ml}$ ), lila = Schlagvolumen (SV; $\mathrm{ml})$, grün = myokardiale Masse $(\mathrm{MM} ; \mathrm{g})$, orange $=$ Ejektionsfraktion $(\mathrm{EF} ; \%)$. Schlagvolumen $=$ end diastolisches Volumen - endsystolisches Volumen. Ejektionsfraktion = [(enddiastolisches Volumen - endsystolisches Volumen)/enddiastolisches Volumen] $\times 100$ (\%). N=38.

* Diese Ergebnisse werden als Referenzstandard betrachtet.
The mean time effort was $63.4 \pm 6.9 \mathrm{~s}$ for the automated segmentation, $74.2 \pm 8.9 \mathrm{~s}$ for ADJ-step 1 and $269.5 \pm 39.4 \mathrm{~s}$ for ADJstep 2 (० Table 3 ).

\section{Discussion}

The aim of this study was to investigate the feasibility of automatic left ventricular parameter segmentation and the effects of different steps of manual adjustment in cardiac MR data of children and adolescents who have undergone surgical repair of CHDDPBF. We studied this cohort because a primarily normally developed left ventricle is expected. However, it is of interest how right-sided CHDs affect the automated segmentation of the possibly altered left ventricle and if adjustment steps are required to obtain satisfying results. MR imaging protocols in patients with CHD-DPBF should routinely include a quantitative assessment of left ventricular volumes and function in order to completely evaluate the complex pathology [3]. Moreover, left ventricular dysfunction measured by MR has been recognized as an important predictor of adverse clinical outcome in patients after TOF repair [4]. We investigated automated segmentation of the left ventricle since sophisticated software packages are available for this purpose. In contrast, automated segmentation software for the right ventricle is in an early stage. Therefore, manual planimetry is usually performed for the right ventricle.

In our patient cohort, commercially available software algorithms, optimized for adult hearts, were able to detect and segment a very high percentage $(95 \%)$ of left ventricles. The applied software failed to detect 2 of 40 ventricles. Interestingly, both patients presented Ebstein's anomaly with a severely dilated right atrium and a displaced left ventricle. This displacement is a potential reason why the software could not detect the appropriate landmarks in order to detect and segment the left ventricle. An extended database for algorithm training purposes, including displaced hearts in particular, could potentially improve the detection rate.

To date, manual short-axis planimetry (=marking of the outer and inner myocardial contour in every short-axis image) is frequently performed for left ventricular parameter assessment [29]. At the base of the heart, slices are considered to be in the left ventricle if the blood was at least $270^{\circ}$ surrounded by ventricular myocardium when using this approach [29]. Although this approach is generally accepted, dedicated software presumably allows more precise determination of the base of the left ventricle in 2-, 3- and 4-chamber views (long-axis images). Therefore, we propose that the left ventricular volumes determined by automated segmentation and a subsequent manual adjustment of the apex (short-axis images) and the base (long-axis images) of the left ventricle as well as manual refinement of the myocardial segmentation can be considered superior and as a reference standard.

Results of automated segmentation and manual adjustment of the apex and base of the left ventricle (ADJ-step 1) are close to the completely manually revised data (adjustment of the apex, base and the myocardial contour =ADJ-step 2). No significant differences were found comparing the results of ADJ-step 1 (manual apex/base adjustment) and ADJ-step 2 (manual apex/base/myocardial contour adjustment). The end-diastolic volume, end-systolic volume and stroke volume were slightly underestimated $(0.4 \mathrm{ml}(0.3 \%)$ for the mean end-diastolic volume, $0.1 \mathrm{ml} \mathrm{(0.2 \% )}$ for the mean end-systolic volume, $0.3 \mathrm{ml}(0.5 \%)$ for the mean stroke volume, and the myocardial mass was slightly overestima- 

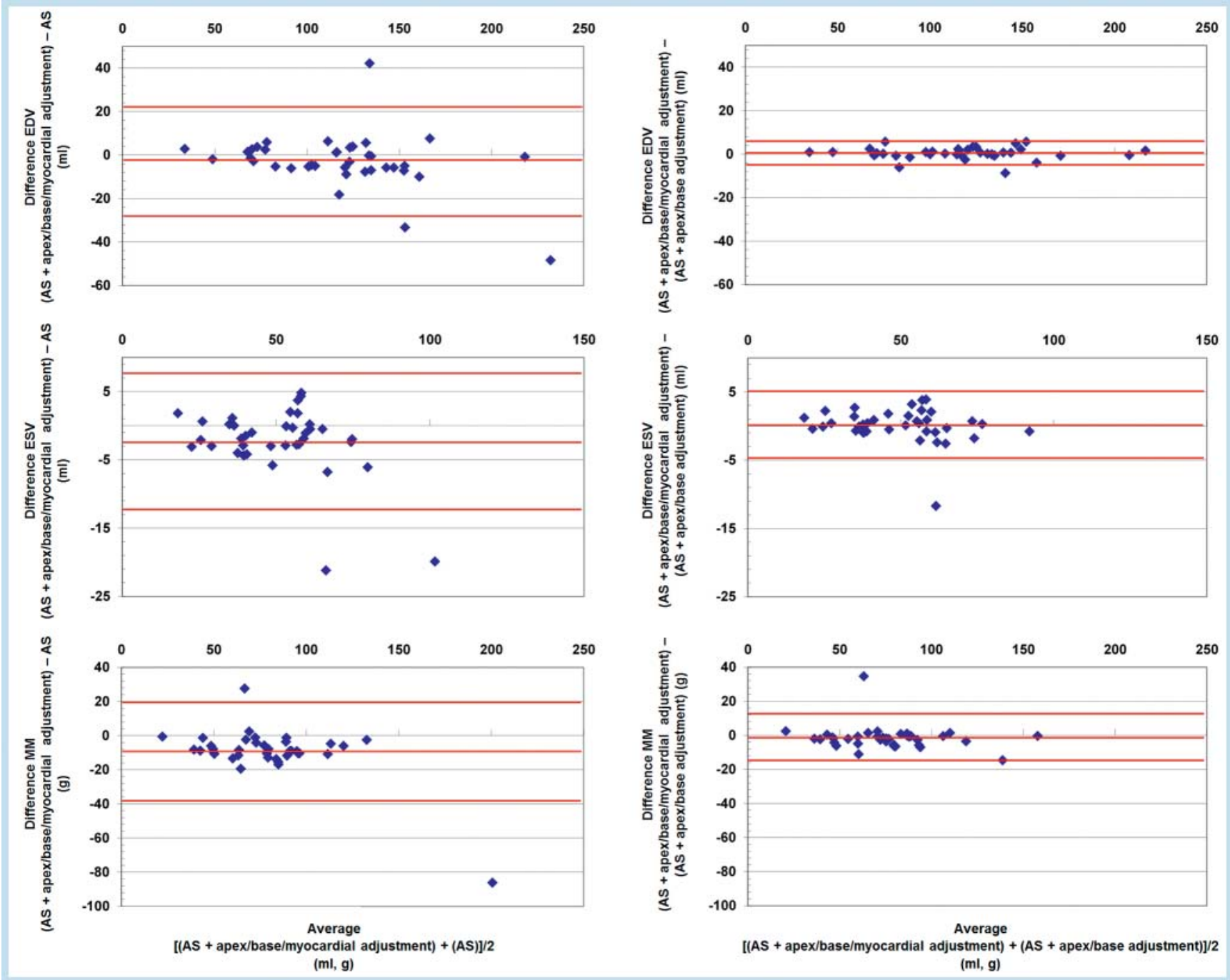

Fig. 3 Bland-Altman plots show the morphologic parameters of the left ventricle, comparing the results of automated segmentation and of automated segmentation + manual adjustment of the apex/base (ADJ-step 1) with the results of automated segmentation + adjustment of the apex/ base/myocardial contour (ADJ-step 2; reference standard). AS = automated segmentation, EDV = end-diastolic volume, ESV = end-systolic volume, $\mathrm{MM}=$ myocardial mass. Red lines show the mean of the differences and the mean of the differences $\pm 1.96 \times$ standard deviation of the differences. Total $n=38$.

Abb. 3 Bland-Altman-Diagramme zeigen die morphologischen Parameter der linken Ventrikel. Es werden die Ergebnisse der automatischen Segmentierung und die der automatischen Segmentierung + der manuellen Apex- 1 Basiskorrektur (Korrekturschritt 1, ADJ-step 1) mit den Ergebnissen der automatischen Segmentierung + der manuellen Apex-/Basis/Myokardkonturkorrektur (Korrekturschritt 2, ADJ-step 2; Referenzstandard) verglichen. $\mathrm{AS}=$ automatische Segmentierung, $\mathrm{EDV}=$ enddiastolisches Volumen, $\mathrm{ESV}=$ endsystolisches Volumen, $\mathrm{MM}=$ myokardiale Masse. Die roten Linien zeigen den Mittelwert der Differenzen $\pm 1.96 \times$ Standardabweichung der Differenzen. $\mathrm{n}=38$.

Table 3 Intra- and inter-rater reliability. 10 randomly selected patients of the cohort (mean age 12.9 years) were evaluated twice by the same readers and independently by 3 different readers. Intraclass correlation coefficients (ICC) were calculated.

Tab. 3 Intra- und Inter-rater-Reliabilität. Zehn zufällig ausgewählte Patienten der Kohorte (durchschnittliches Alter 12,9 Jahre) wurden zweimal von den gleichen Auswertern und unabhängig voneinander von 3 unterschiedlichen Auswertern evaluiert. Intraklassen-Korrelationskoeffizienten (ICC) wurden berechnet.

\begin{tabular}{|llllc|} 
& & $\begin{array}{l}\text { automated } \\
\text { segmentation }\end{array}$ & $\begin{array}{l}\text { automated segmentation + } \\
\text { apex/base adjustment } \\
\text { (ADJ-step 1) }\end{array}$ & $\begin{array}{l}\text { automated segmentation + } \\
\text { apex/base/myocardial contour } \\
\text { adjustment (ADJ-step 2) }\end{array}$ \\
\hline end-diastolic volume & intra-rater reliability & 0.99 & 0.99 & 0.99 \\
\cline { 2 - 5 } & inter-rater reliability & 0.99 & 0.98 & 0.98 \\
\hline end-systolic volume & intra-rater reliability & 0.99 & 0.99 & 0.99 \\
\cline { 2 - 5 } & inter-rater reliability & 0.99 & 0.96 & 0.91 \\
\hline myocardial mass & intra-rater reliability & 0.99 & 0.99 & 0.99 \\
\cline { 2 - 5 } & inter-rater reliability & 0.99 & 0.96 & $269.5 \pm 39.4$ \\
\hline
\end{tabular}


ted (1.6g $(2.1 \%)$ for the mean myocardial mass) when comparing results of $A D J$-step 1 (manual apex/base adjustment) with those of ADJ-step 2 (manual apex/base/myocardial contour adjustment). However, these deviations are unlikely to be of clinical relevance. The mean ejection fraction did not differ when comparing the results of ADJ-step 1 (manual apex/base adjustment) with those of ADJ-step 2 (manual apex/base/myocardial contour adjustment). It is worth mentioning that the adjustment of the apex and base of the ventricle can be performed quickly in general (mean time effort in 10 randomly selected patients: $74.2 \pm 8.9 \mathrm{~s}$ ). In contrast, the manual adjustment of the myocardial contour (= equal to manual short-axis planimetry) is usually time-consuming due to the required marking of the outer and inner myocardial contour in every slice (mean time effort in 10 randomly selected patients: $269.5 \pm 39.4 \mathrm{~s}$ ). The results after automated segmentation and following the ADJ-steps showed excellent intra- and inter-rater reliability.

Assuming that the results after the manual adjustment of the apex, base and myocardial contour of the left ventricle represent a reference standard, results of ADJ-step 1 (automated segmentation + manual apex/base adjustment) could provide clinically acceptable parameters for the majority of cases. Nevertheless, a review of the automatically segmented myocardium and casebased refinement of the inner and outer myocardial contour remains necessary. Interestingly, in the investigated cohort the accuracy of the results of ADJ-step 1 is even superior in comparison to the corresponding accuracy of a previously published cohort consisting of patients that exhibit quite similar characteristics but anatomically inconspicuous hearts [30]. In the investigated cohort, no significant differences were found when comparing the results of ADJ-step 1 and ADJ-step 2, whereas small but significant differences were found for the end-diastolic volume, endsystolic volume, myocardial mass and ejection fraction in the cohort consisting of patients with anatomically inconspicuous hearts [30].

Our study has some limitations that suggest directions for future work.

Automated segmentation and the different adjustment steps were performed with one dedicated commercially available software package. We utilized this system because it is routinely used in our department. It would be interesting to compare the results of different software packages. However, this study was not intended to analyze the accuracy of different software packages, but to show intra- and inter-rater reliability and the effects and the necessity of subsequent adjustment steps. Left ventricular analysis was performed with "native" bSSFP cine images. In the clinical routine, however, acquisition of cine images is sometimes performed after the administration of contrast agent to save time within the context of viability imaging. The added value of viability imaging in patients with CHD has been demonstrated previously and, therefore, has become an integral part of imaging protocols for CHD patients [31, 32]. Automated segmentation might be constrained in post-contrast bSSFP cine images due to the decreased contrast between myocardium and blood pool. The preparation of "native" bSSFP cine images may prolong the scan time due to a longer latency before viability imaging.

\section{Conclusion}

\section{$\nabla$}

Based on the results of our study, automated left ventricular segmentation in MR data of children and adolescents with CHDDPBF is feasible with excellent intra- and inter-rater reliability using dedicated commercially available software. Automated segmentation with manual apex/base adjustment provided clinically acceptable parameters for the majority of cases and potentially improves and accelerates the workflow in the clinical routine. Limitations were observed for patients with a distinctively displaced or "squashed" left ventricle in the presence of massive right heart dilatation. Future research should investigate the accuracy and time efficiency of different software packages for left ventricular segmentation in children and adolescents as well as their potential to improve intra- and inter-reader agreement.

\section{Clinical Relevance of the Study}

- Automated left ventricular volumes and function analysis in MR data of children and adolescents who have undergone surgical repair of right-sided congenital heart disease is feasible with excellent intra- and inter-rater reliability.

- Automated segmentation with manual apex/base adjustment provides clinically acceptable results. Additional manual myocardial contour adjustment does not significantly improve the results.

- Automated segmentation with a few manual adjustments may accelerate workflow and reading.

\section{Abbreviations and Acronyms \\ $\nabla$}

CCHD-DPBF Congenital cyanotic heart disease with decreased pulmonary blood flow

TOF Tetralogy of Fallot

PA Pulmonary atresia

VSD Ventricular septal defect

ADJ-step Adjustment step

\section{References}

1 Hoffmann JI, Kaplan S. The incidence of congenital heart disease. J Am Coll Cardiol 2002; 39: 1890-1900

2 Bacha EA, Scheule AM, Zurakowski D et al. Long-term results after early primary repair of tetralogy of Fallot. J Thorac Cardiovasc Surg 2001; 122: $154-161$

3 Bogaert J, Dymarkowski S, Taylor AM et al. Clinical Cardiac MRI. 2nd edition. Berlin-Heidelberg: Springer; 2012: $582-584$

4 Knauth AL, Gauvreau K, Powell AJ et al. Ventricular size and function assessed by cardiac MRI predict major adverse clinical outcome late after tetralogy of Fallot repair. Heart 2008; 94: 211-216

5 Warnes CA, Williams RG, Bashore TM et al. ACC/AHA 2008 guidelines for the management of adults with congenital heart disease. Circulation 2008; 118: $2395-2451$

6 Debatin JF, Nadel SN, Paolini JF et al. Cardiac ejection fraction: phantom study comparing cine MR imaging, radionuclide blood pool imaging, and ventriculography. J Magn Reson Imaging 1992; 2: 135-142

7 Beerbaum $P$, Körperich $H$, Barth $P$ et al. Noninvasive quantification of left-to-right shunt in pediatric patients: phase-contrast cine magnetic resonance imaging compared with invasive oximetry. Circulation 2001; 103: 2476-2482

8 Mooij CF, de Wit CJ, Graham DA et al. Reproducibility of MRI measurements of right ventricular size and function in patients with normal and dilated ventricles. J Magn Reson Imaging 2008; 28: 67-73 
9 Bellenger NG, Burgess MI, Ray SG et al. Comparison of left ventricular ejection fraction and volumes in heart failure by echocardiography, radionuclide ventriculography and cardiovascular magnetic resonance; are they interchangeable? Eur Heart J 2000; 21: 1387-1396

10 Winter MM, Bernink FJ, Groenink $M$ et al. Evaluating the systemic right ventricle by CMR: the importance of consistent and reproducible delineation of the cavity. J Cardiovasc Magn Reson 2008; 10: 40

11 van der Geest RJ, Buller VG, Jansen E et al. Comparison between manual and semiautomated analysis of left ventricular volume parameters from short-axis MR images. J Comput Assist Tomogr 1997; 21: 756 765

12 Waiter GD, McKiddie FI, Redpath TW et al. Determination of normal regional left ventricular function from cine-MR images using a semi-automated edge detection method. Magn Reson Imaging 1999; 17: 99 107

13 Lalande A, Legrand L, Walker PM et al. Automatic detection of left ventricular contours from cardiac cine magnetic resonance imaging using fuzzy logic. Invest Radiol 1999; 34: 211-217

14 Young AA, Cowan BR, Thrupp SF et al. Left ventricular mass and volume: fast calculation with guide-point modeling on MR images. Radiology 2000; 216: 597-602

15 van der Geest RJ, Lelieveldt BP, Angelié E et al. Evaluation of a new method for automated detection of left ventricular boundaries in time series of magnetic resonance images using an Active Appearance Motion Model. J Cardiovasc Magn Reson 2004; 6: 609-617

16 Uzümcü $M$, van der Geest RJ, Sonka $M$ et al. Multiview active appearance models for simultaneous segmentation of cardiac 2- and 4-chamber long-axis magnetic resonance images. Invest Radiol 2005; 40: $195-203$

17 Lynch $M$, Ghita $O$, Whelan PF. Left-ventricle myocardium segmentation using a coupled level-set with a priori knowledge. Comput Med Imaging Graph 2006; 30: 255 -262

18 Pednekar A, Kurkure U, Muthupillai $R$ et al. Automated left ventricular segmentation in cardiac MRI. IEEE Trans Biomed Eng 2006; 53: 1425 1428

19 Angelié E, Oost ER, Hendriksen D et al. Automated contour detection in cardiac MRI using active appearance models: the effect of the composition of the training set. Invest Radiol 2007; 42: 697-703
20 Beyar $R$, Shapiro EP, Graves WL et al. Quantification and validation of left ventricular wall thickening by a three-dimensional volume element magnetic resonance imaging approach. Circulation 1990; 81: 297-307

21 Petitjean C, Dacher JN. A review of segmentation methods in short axis cardiac MR images. Med Image Anal 2011; 15: 169-84

22 Brodoefel H, Tsiflikas I, Kramer U et al. Accuracy of automated attenuation-based 3-dimensional segmentation: in the analysis of left ventricular function compared with magnetic resonance imaging. Tex Heart Inst J 2012; 39: 36- 43

23 Hautvast GL, Salton CJ. Chuang ML et al. Accurate computer-aided quantification of left ventricular parameters: experience in 1555 cardiac magnetic resonance studies from the Framingham Heart Study. Magn Reson Med 2012; 67: 1478-486

$24 \mathrm{Lu}$ YL, Connelly KA, Dick AJ et al. Automatic functional analysis of left ventricle in cardiac cine MRI. Quant Imaging Med Surg 2013; 3: 200 -9

25 Cocosco CA, Niessen WJ, Netsch $T$ et al. Automatic image-driven segmentation of the ventricles in cardiac cine MRI. J Magn Reson Imaging 2008; $28: 366-374$

$26 \mathrm{Liu} \mathrm{H,Hu} \mathrm{H,XuX} \mathrm{et} \mathrm{al.} \mathrm{Automatic} \mathrm{left} \mathrm{ventricle} \mathrm{segmentation} \mathrm{in} \mathrm{cardiac}$ MRI using topological stable-state thresholding and region restricted dynamic programming. Acad Radiol 2012; 19: 723 - 731

27 Barbier CE, Johansson L, Lind $L$ et al. The exactness of left ventricular segmentation in cine magnetic resonance imaging and its impact on systolic function values. Acta Radiol 2007; 48: 285-291

28 Mosteller RD. Simplified calculation of body-surface area. N Engl J Med 1987; 317: 1098

29 Nassenstein $K$, de Greiff A, Hunold P. MR evaluation of left ventricular volumes and function: threshold-based 3D segmentation versus short-axis planimetry. Invest Radiol 2009; 44: 635-640

30 Hammon M, Janka R, Dankerl P et al. Pediatric cardiac MRI: automated left-ventricular volumes and function analysis and effects of manual adjustments. Pediatr Radiol 2015; 45: 651-657

31 Harris MA, Johnson TR, Weinberg PM et al. Delayed-enhancement cardiovascular magnetic resonance identifies fibrous tissue in children after surgery for congenital heart disease. J Thorac Cardiovasc Surg 2007: 133: 676-681

32 Dorfman AL, Geva T. Magnetic resonance imaging evaluation of congenital heart disease: conotruncal anomalies. J Cardiovasc Magn Reson 2006; 8: $645-659$ 